\title{
Expression of paxillin and FAK mRNA and the related clinical significance in esophageal carcinoma
}

\author{
HONG-XING CAI ${ }^{1,2}$, LIU-CAI YANG ${ }^{1}$, XIANG-HE SONG ${ }^{1}$, ZHOU-RU LIU $^{2}$, YAN-BO CHEN ${ }^{2}$ and GUO-KAI DONG ${ }^{2}$ \\ ${ }^{1}$ Yancheng Health Vocational and Technical College, Yancheng 224006; \\ ${ }^{2}$ Department of Forensic Medicine, Xuzhou Medical College, Xuzhou 221002, P.R. China
}

Received July 30, 2011; Accepted November 1, 2011

DOI: $10.3892 / \mathrm{mmr} .2011 .664$

\begin{abstract}
The objective of the present study was to investigate the expression of paxillin and focal adhesion kinase (FAK) mRNA in esophageal carcinoma tissues, and their relationship with clinicopathological parameters, as well as to analyze the correlation of paxillin and FAK mRNA levels in esophageal carcinoma. By using reverse transcription polymerase chain reaction (RT-PCR), the mRNA expression levels of paxillin and FAK were detected in 121 samples of esophageal carcinoma, 43 samples of atypical hyperplasia and 56 samples of normal esophageal mucosa. The results showed that the positive rates of paxillin and FAK mRNA expression in esophageal carcinoma were 87.6 and $80.17 \%$, respectively, which were significantly higher $(\mathrm{P}<0.05)$ than those in atypical hyperplasia (44.19 and 39.53\%) and normal esophageal mucosa (5.36 and 12.5\%). Notably, paxillin and FAK mRNA expression levels were significantly correlated with the differentiation degree and depth of invasion of esophageal carcinoma and with lymph node metastasis $(\mathrm{P}<0.05)$. In addition, paxillin and FAK mRNA expression levels in esophageal carcinoma were positively correlated $(r=0.4804, \mathrm{P}=0.000)$. In conclusion, the combined detection of paxillin and FAK mRNA expression is expected to provide a theoretical basis for the molecular diagnosis of esophageal carcinoma.
\end{abstract}

\section{Introduction}

Paxillin is a tyrosine kinase substrate and a significant cell adhesion molecule. Paxillin is associated with integrin and its related cellular and extracellular matrix molecules. As such, paxillin helps to regulate cell migration, dissemination and other functions, and enhances tumor cell invasion and metastasis $(1,2)$. Focal adhesion kinase (FAK) is distributed in the cellular focal adhesion sites and plays a crucial role in

Correspondence to: Dr Hong-Xing Cai, Yancheng Health Vocational and Technical College, Jiefangnan Road 263, Yancheng, Jiangsu 224006, P. R. China

E-mail: yccaihx1962@126.com

Key words: esophageal carcinoma, paxillin, focal adhesion kinase, RT-PCR the regulation of tumor cell migration $(3,4)$. Thus, paxillin and FAK are both related to the occurrence of tumors and their biological behavior. In this study, reverse transcription polymerase chain reaction (RT-PCR) was used to detect paxillin and FAK mRNA expression in esophageal carcinoma, atypical dysplasia and normal esophageal mucosa. This study also investigated the relationship of paxillin, FAK and clinicopathological parameters, as well as the correlation between paxillin and FAK expression, in order to provide a theoretical basis for a molecular diagnostic for esophageal carcinoma.

\section{Materials and methods}

General information. Fresh specimens were collected from esophagectomies of 121 patients while visiting the Department of Oncology, Affiliated Hospital, Xuzhou Medical College (Jiangsu Province, China) from March 1, 2010 to March 1, 2011. Subjects included 68 males and 53 females, aged 35 to 80 years; all had no preoperative chemotherapy, radiotherapy or immunotherapy history. Shortly following specimen harvest, two samples were taken from each of three sites - necrosis-free carcinoma (within $3 \mathrm{~cm}$ of the expected carcinoma) and distant, normal mucosa. For each tissue, one of the two samples was stored in liquid nitrogen for later RT-PCR preparation. The second sample was fixed using $40 \mathrm{~g} / \mathrm{l}$ formaldehyde solution for routine pathological diagnosis.

Reagents and primers. Total RNA was obtained using RNA isolator (Takara Biotech Co., Dalian, China), one-step RNA PCR kits were purchased from Takara Biotech Co., (China). The primer sequences were: paxillin (GenBank Accession no. BC136794) F: 5'-TGAAACTGGAACCCTTGTCC-3', R: 5'-TAT GCTGGCATTGTCTGGAG-3', product size 383 bp; FAK (GenBank Accession No.: L05186) F: 5'-TCCTAATGTTG ATGCCTGCC-3', R: 5'-CCTTGAAAAGGCTTCACACC-3', product size $498 \mathrm{bp}$; and $\beta$-actin (GenBank Accession no. NM_001101) F: 5'-AAATCTGGCACCACACCTT-3', R: 5'-TAG CACAGCCTGGATAGCAA-3', product size $170 \mathrm{bp}$. The above primers were synthesized by Takara Biotech Co.

Total RNA extraction. The tissue was homogenized fully in a glass homogenizer and the remaining steps were performed in strict accordance with RNA isolator instructions. RNA 
Table I. Relationship between the paxillin and FAK mRNA expression and pathological features in esophageal carcinoma tissue.

\begin{tabular}{lccccccc}
\hline $\begin{array}{l}\text { Pathological } \\
\text { features }\end{array}$ & $\mathrm{n}$ & $\begin{array}{c}\text { paxillin } \\
\text { mRNA }\end{array}$ & $\chi^{2}$ value & P-value & $\begin{array}{c}\text { FAK } \\
\text { mRNA }\end{array}$ & $\chi^{2}$ value & P-value \\
\hline $\begin{array}{l}\text { Degree of differentiation } \\
\quad \text { Well differentiated }\end{array}$ & 32 & 23 & 22.4100 & $<0.005$ & 19 & 31.580 & $<0.005$ \\
$\quad \begin{array}{l}\text { Moderately differentiated } \\
\quad \text { Poorly differentiated }\end{array}$ & 54 & 48 & & & 43 & & \\
$\quad \begin{array}{l}\text { Depth of invasion } \\
\quad \text { Deep muscular layer }\end{array}$ & 27 & 27 & 12.0000 & $<0.005$ & 27 & 16.100 & $<0.005$ \\
$\quad$ Shallow muscular layer & 31 & 28 & & & 24 & & \\
$\quad$ Fiber membrane & 63 & 51 & & & 46 & & \\
$\quad$ Lymph node metastasis & & & & & & & \\
$\quad$ Yes & 31 & 31 & 4.4629 & $<0.050$ & 31 & 10.312 & \\
$\quad$ No & 90 & 75 & & & 66 & & \\
\hline
\end{tabular}

Table II. Correlation between the expression of paxillin and FAK mRNA in esophageal carcinoma tissue.

\begin{tabular}{lrrrrr}
\hline & \multicolumn{2}{c}{ FAK mRNA } & Total & r-value & P-value \\
\cline { 2 - 4 } & + & - & & & \\
\hline Paxillin mRNA & 92 & 14 & 106 & 0.4804 & 0.000 \\
+ & 5 & 10 & 15 & \\
- & 97 & 24 & 121 & \\
Total & 97 & & \\
\hline
\end{tabular}

content and purity were ascertained by spectrophotometer 260:280 ratio. The obtained RNA was dissolved in $50 \mu 1$ diethylpyrocarbonate (DEPC)-treated water.

$R T$-PCR. The total volume for reverse transcription was $25 \mu 1$ and procedures were performed in strict accordance with the kit instructions. The RT-PCR reaction conditions were: RT reaction at $50^{\circ} \mathrm{C}$ for $30 \mathrm{~min}$, RTase inactivation at $94^{\circ} \mathrm{C}$ for $2 \mathrm{~min} ; 94^{\circ} \mathrm{C}$ for $30 \mathrm{sec}, 55^{\circ} \mathrm{C}$ for $90 \mathrm{sec}$ and $72^{\circ} \mathrm{C}$ for $30 \mathrm{sec}$, for 35 cycles in total, followed by maintenance at $72^{\circ} \mathrm{C}$ for $10 \mathrm{~min}$. Amplified product $(5 \mu \mathrm{l})$ was separated by agarose gel electrophoresis, then photographed and analyzed using gel imaging software. The ratio of target genes and the internal reference $\beta$-actin was used to determine the relative expression level of the target genes.

Statistical methods. SPSS 13.0 statistical software was used to perform the $\chi^{2}$ test, analysis of variance and rank sum test, as appropriate.

\section{Results}

Sample histology. All of the tumor tissues were confirmed as esophageal squamous cell carcinoma by hematoxylin and eosin (H\&E) staining and histopathological analysis. The specimens were histologically graded according to the WHO classification criteria (1996). Samples were highly differentiated in 32 cases, moderately differentiated in 54 cases and poorly differentiated in 35 cases. Assessment of infiltration depth was to the deep muscular layer in 27 cases, the superficial muscular layer in 31 cases and the fibrous membrane layer in 63 cases. A total of 31 cases had accompanying lymph node metastasis, but 90 did not have lymph node metastasis. A total of 43 samples of normal, adjacent tissue grade were actually atypical dysplasia, while 56 cases were normal esophageal mucosa.

Paxillin mRNA expression in esophageal carcinoma. RT-PCR results revealed that the relative expression level of paxillin mRNA in the esophageal carcinoma tissue was 0.874 $\pm 0.034)$, significantly higher than that in atypical hyperplasia $(0.228 \pm 0.056)$ and normal mucosa $(0.107 \pm 0.032)$. The difference was statistically significant among the three groups ( $F=107.289, P=0.000)$ (Fig. 1). In addition, the positive rate of paxillin mRNA in esophageal carcinoma was $87.6 \%(106 / 121$ cases), significantly higher than that in atypical dysplasia $(44.19 \%, 19 / 121$ cases) and normal mucosa $(5.36 \%, 3 / 121$ cases) $\left(\chi^{2}=110.7345\right.$ and $\left.\mathrm{P}=0.000\right)$.

FAK mRNA expression in esophageal carcinoma. RT-PCR was used to detect FAK mRNA expression and the results showed the relative expression level of FAK mRNA in esophageal carcinoma tissue was $0.945 \pm 0.062$, significantly higher than that in atypical hyperplasia $(0.438 \pm 0.054)$ and normal mucosa $(0.095 \pm 0.024)$. The difference was statistically signif- 


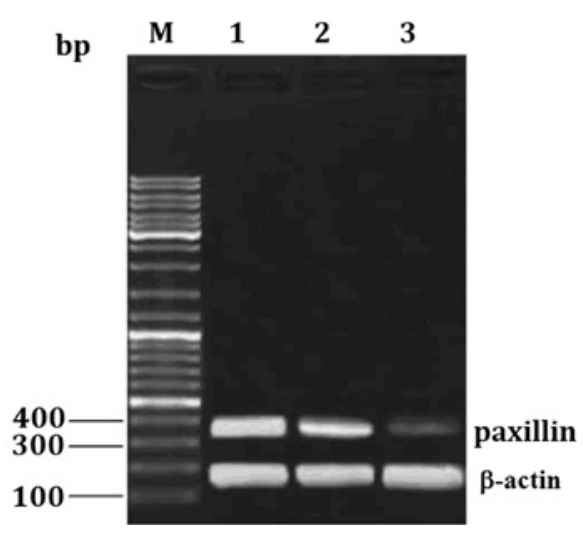

Figure 1. Detection of paxillin mRNA expression in esophageal carcinoma tissues by RT-PCR. Lane M, marker; 1, esophageal carcinoma tissue; 2, dysplasia atypical hyperplasia tissue; 3 , normal mucosa tissue.

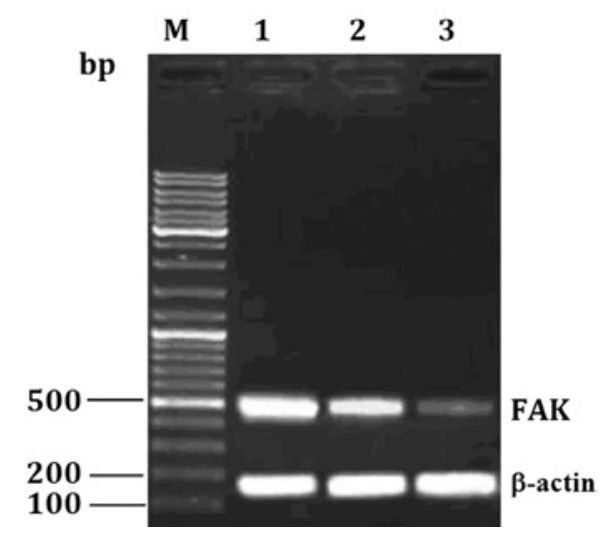

Figure 2. Detection of FAK mRNA expression in esophageal carcinoma tissues by RT-PCR. Lane M, marker; 1, esophageal carcinoma tissue; 2, dysplasia atypical hyperplasia tissue; 3 , normal mucosa tissue.

icant among the three groups ( $\mathrm{F}=127.238, \mathrm{P}=0.000)$. (Fig. 2). The positive rate of FAK mRNA in esophageal carcinoma was $80.17 \%$ (97/121 cases), significantly higher than that in the atypical dysplasia (39.53\%, 17/121 cases) and normal mucosa $(2.5 \%, 7 / 121$ cases $)\left(\chi^{2}=110.7345\right.$ and $\left.\mathrm{P}=0.000\right)$.

Relationship of paxillin, FAK mRNA expression and clinicopathological characteristics of esophageal carcinoma, and the correlation between paxillin and FAK mRNA. The relationships of paxillin mRNA, FAK mRNA and clinicopathological parameters of esophageal carcinoma were analyzed by SPSS 13.0 software. Results revealed that paxillin and FAK mRNA expression levels were significantly related to esophageal carcinoma differentiation, invasion depth and lymph node metastasis $(\mathrm{P}<0.05$, Table I). Furthermore, Table II shows that paxillin and FAK mRNA expression were significantly correlated $(\mathrm{r}=0.4804, \mathrm{P}=0.000)$.

\section{Discussion}

Esophageal carcinoma development involves changes in many genes, yet the specific regulatory mechanisms are still not completely clear (5-7). Paxillin and FAK are two key signaling molecules in integrin-mediated signaling pathways and are closely associated with cell adhesion, tumor cell migration, cell proliferation and cell survival (8-11). Some studies have shown that FAK plays a significant role in the integrin signaling pathway (12). Once activated by the stimulating factor of integrin or non-integrin, FAK will combine with and stimulate other molecules including Src, P130Cas, Grb2, PI3K and paxillin.

The combined detection of FAK and paxillin may have more value in detecting tumor cells. Li et al (13) reported that in 100 samples of esophageal carcinoma, 27 exhibited high paxillin gene expression but only 6 samples of adjacent atypical hyperplasia exhibited paxillin expression. In addition, Chatzizacharias et al found that 54/91 cases of esophageal carcinoma had FAK overexpression, and its positive rate of expression was 59.3\%. Furthermore, the results also showed that FAK expression was closely related to the differentiation degree of esophageal carcinoma, invasion depth and lymph node metastasis. However, these studies have not simultaneously detected paxillin and FAK expression in esophageal carcinoma or analyzed the relationships between expression of paxillin and FAK.

Results from the current study revealed that the positive rate of paxillin mRNA in esophageal carcinoma tissue was $87.6 \%$, significantly higher than that in atypical dysplasia and normal mucosa. The relative expression level of paxillin mRNA in the esophageal carcinoma tissue was also significantly higher than that in the atypical dysplasia and normal mucosa. The positive rate of FAK mRNA in esophageal carcinoma tissue was $80.17 \%$, significantly higher than that in atypical dysplasia (39.53\%) and normal mucosa (12.5\%). The relative expression level of FAK mRNA in esophageal carcinoma tissue was also significantly higher than that in the atypical dysplasia and normal mucosa. In addition, the above results suggest that the expression levels of paxillin and FAK mRNA were closely related to development of esophageal squamous cell carcinoma.

Results from the present study also demonstrated a relationship between the expression of paxillin and FAK mRNA and clinicopathological parameters. Paxillin and FAK mRNA were significantly correlated with the differentiation degree of esophageal carcinoma, invasion depth and lymph node metastasis $(\mathrm{P}<0.05)$, which suggests a close relationship between paxillin and FAK mRNA expression and occurrence and development of esophageal carcinoma. Furthermore, the correlation analysis demonstrated a positive correlation between paxillin and FAK mRNA expression ( $\mathrm{r}=0.4804$, $\mathrm{P}=0.000$ ), which indicates a significant synergistic effect of these genes and development of esophageal carcinoma. Further studies on the molecular mechanisms of paxillin and FAK in esophageal carcinoma are expected to provide a theoretical basis for the molecular diagnosis of esophageal carcinoma through combined detection of paxillin and FAK mRNA expression.

\section{References}

1. Iwasaki T, Nakata A, Mukai M, et al: Involvement of phosphorylation of Tyr-31 and Tyr-118 of paxillin in MM1 cancer cell migration. Int J Cancer 97: 330-335, 2002. 
2. Chen HY, Shen CH, Tsai YT, Lin FC, Huang YP and Chen RH: Brk activates racl and promotes cell migration and invasion by phosphorylating paxillin. Mol Cell Biol 24: 10558-10572, 2004.

3. Das T, Bae YH, Wells A and Roy P: Profilin-1 overexpression upregulates PTEN and suppresses AKT activation in breast cancer cells. J Cell Physiol 218: 436-443, 2009.

4. Zou L, Jaramillo M, Whaley D, Wells A, Panchapakesa V, Das T and Roy P: Profilin-1 is a negative regulator of mammary carcinoma aggressiveness. Br J Cancer 97: 1361-1371, 2007.

5. Chang X, Hou X, Pan J, Fang K, Wang L and Han J: Investigating the pathogenic role of PADI4 in oesophageal cancer. Int Biol Sci 7: 769-781, 2011.

6. Chava S, Mohan V, Shetty PJ, Manolla ML, Vaidya S, Khan IA, Waseem GL, Boddala P, Ahuja YR and Hassan Q: Immunohistochemical evaluation of p53, FHIT, and IGF2 gene expression in esophageal cancer. Dis Esophagus: June 10, 2011, doi: 10.1111/j.1442-2050.2011.01213.x (Epub ahead of print).

7. Rao S, Welsh L, Cunningham D, Te-poele RH, Benson M, Norman A, Saffery C, Giddings I, Workman P and Clarke PA: Correlation of overall survival with gene expression profiles in a prospective study of resectable esophageal cancer. Clin Colorectal Cancer 10: 48-56, 2011.
8. Mitra SK and Schlaepfer DD: Intergrin-regulated FAK-Src signaling in normal and cancer cells. Curr Opin Cell Biol 18: 516-523, 2006.

9. Kim LC, Song L and Haura EB: Src kinases as therapeutic targets for cancer. Nat Rev Clin Oncol 6: 587-595, 2009.

10. Kim MS, Yoo NJ and Lee SH: Absence of paxillin gene mutation in lung cancer and other common solid cancers. Tumori 97: 211-213, 2011.

11. Chen JY, Tang YA, Huang SM, et al: A novel sialyltransferase inhibitor suppresses FAK/paxillin signaling and cancer angiogenesis and metastasis pathways. Cancer Res 71: 473-483, 2011.

12. Chatzizacharias NA, Kouraklis GP and Theocharis SE: Clinical significance of FAK expression in human neoplasia. Histol Histopathol 23: 629-650, 2008.

13. Li BZ, Lei W, Zhang CY, et al: Increased expression of paxillin is found in human oesophageal squamous cell carcinoma: a tissue microarray study. J Int Med Res 36: 273-278, 2008. 